\title{
Phonemic-similarity effects in good vs. poor readers
}

\author{
JAMES W. HALL, KIM P. WILSON, MICHAEL S. HUMPHREYS, \\ MARGARET B. TINZMANN, and PAUL M. BOWYER \\ Northwestern University, Evanston, Illinois
}

\begin{abstract}
Experiments 1.4 examined immediate serial recall of rhyming and nonrhyming items by normal and poor readers in Grades 2-4. Children with generally low achievement were excluded from the poor-reader groups, so that the achievement deficit of the poor readers was centered in reading. The poor readers did not differ from the normal readers in their susceptibility to phonemic similarity either with letter lists or with word lists. Children low in both achievement and intelligence were included in Experiment 3, and they also showed normal susceptibility to phonemic similarity, except that phonemic-confusion effects were reduced when task-difficulty levels were high. Experiment 5 further demonstrated that the serial-recall task is relatively insensitive to phonemic-similarity effects when difficulty levels are high. Previous results suggesting that poor readers are relatively insensitive to phonemic similarity in such tasks may have been an artifactual consequence of marked differences in overall task difficulty for the groups compared. Implications of variations in sample-selection procedures also are discussed.
\end{abstract}

A number of explanations have been advanced to account for poor reading skills among otherwise intellectually able individuals (see, for example, reviews by Morrison \& Manis, 1982, and Vellutino, 1979). One of the more interesting current notions is that such individuals are deficient with respect to the processing of phonetic information. A series of three experiments reported by Shankweiler, Liberman, Mark, Fowler, and Fischer (1979) has been influential in this respect. In each of these experiments, the confusion effect (relatively poor recall of rhyming items) generally found in a serial-recall task with rhyming letters was markedly less for poor than for good readers. It was concluded, therefore, that poor readers make less effective use than good readers of phonetic information in recalling letters. The principal purpose of the experiments to be reported here was to examine further the issue of differential susceptibility of good and poor readers to phonemicsimilarity effects.

If the Shankweiler et al. (1979) results are accepted at face value, there remains the question of to which

This research was supported in part by a research contract from the Bureau of Education for the Handicapped, Office of Education (US HEW OF 300770 493) for the University of Illinois's Chicago Institute for Learning Disabilities. We are grateful to the school officials, teachers, and children in Evanston and Mt. Prospect whose cooperation made this research possible, and to the Wisconsin Center for Education Research, University of Wisconsin-Madison, which is supported in part by a grant from the National Institute of Education (Grant NIE-G-0009), for assistance in preparation of this manuscript. Michael $S$. Humphreys now is at the University of Queensland, and Kim P. Wilson is at the University of Michigan. Requests for reprints should be addressed to James W. Hall, Department of Psychology, Northwestern University, Evanston, Illinois 60201. particular population of poor readers those results may be generalized. In the Shankweiler et al. experiments and in many, if not most, other studies concerning children with reading deficiencies (or reading disability or dyslexia), interest seems to be in a particular subpopulation of poor readers. That subpopulation consists of individuals with an achievement deficit specific to, or at least primarily restricted to, reading. This specific focus of interest is not always made explicit, but generally may be inferred by the investigator's attempt to exclude from the sample of poor readers those individuals with generally low intellectual ability. The idea seems to be to isolate and study those individuals (generally children) whose performance in decoding written words is low relative to their performance on other sorts of intellectual tasks.

Given that the focus of interest in this research is on reading ability, it seems surprising that in very few such studies is achievement in other skill areas taken into account in sampling the poor readers selected for study. That is, in nearly every one of the many dozens of studies we have examined, the only achievement data systematically taken into account are reading-achievement data. Given the substantial relationship between reading achievement and achievement in other intellectual skills, one can be reasonably certain that samples of poor readers selected in this way will include children whose achievement difficulties extend to areas other than reading. In fact, with such procedures, a sample of poor readers could well include some children whose achievement is lower in mathematics, for example, than in reading. In short, such sampling procedures seem somewhat inconsistent with the goal of understanding the source of deficits centering in reading (word decod- 
ing) and leave ambiguity regarding the particular subpopulation of poor readers to which any result may be generalized.

For the above reason, we designed our initial experiments to look specifically at children whose achievement deficits were centered in reading. This was done by considering achievement in mathematics, as well as performance on a test of general intelligence, in the selection of low reading samples. In addition, Experiment 3 included a group of poor readers whose general intelligence and mathematics achievement also were low relative to their age-grade peers.

Our approach to sample selection permitted us to determine whether unusually low susceptibility to phonemic confusions is peculiar to children with a specific reading deficit or whether it also (or instead) characterizes children with more pervasive achievement deficits. Another possibility that our experiments addressed is that the differences in phonemic confusions between the poor and good readers reported by Shankweiler et al. (1979), and also by Mann, Liberman, and Shankweiler (1980), arose from a measurement (scaling) problem and really did not reflect differential sensitivity of the groups to phonemic similarity. This possibility is discussed next.

The critical evidence for differential sensitivity to phonemic similarity in the Shankweiler et al. (1979) experiments was an interaction between groups and list type (rhyming vs. nonrhyming letters): The rhymingnonrhyming difference was less for the poor readers than for the good readers. Put another way, the deleterious effects of the rhyming relationship among letters were smaller for the poor readers than for the good readers. However, interpretation of that interaction is complicated by the fact that the overall difficulty level of the serial-recall task (i.e., the difficulty of the nonrhyming lists) was markedly higher for the poor readers than for the good readers. In fact, Shankweiler et al. reported that the poor readers' low level of performance "gives them less room to show an effect of phonetic confusability" (p. 542). Shankweiler et al. went on to acknowledge the possibility that this floor effect, rather than a true difference in susceptibility to phonemic similarity, might have produced the interaction that was so critical to their conclusions.

Our concern regarding the interpretation of interactions of the sort reported by Shankweiler et al. (1979) is not restricted entirely to the case of obvious floor effects. Interpretive questions regarding such interactions exist whenever groups differ markedly in overall performance, such that the measurement scales cannot be assumed to be equivalent in a psychological sense (see Baron \& Treiman, 1980, and Loftus, 1978). Considering the present situation, it seems possible that when the nonrhyming lists are much more difficult for one group than for another, the task may not be as sensitive to the effects of phonemic similarity for one group as for the other. If this is correct, then it calls into question the results of a second series of experiments, this time with word lists and sentences, in which susceptibility to phonemic similarity appeared to be lower for poor readers than for good readers (Mann et al., 1980). In the Mann et al. experiments, there was no obvious floor effect of the sort found in the Shankweiler et al. experiments, but a very great superiority of good to poor readers on nonrhyming items was present, suggesting the possibility that the critical interactions in those experiments also arose from a scaling problem. This possibility will be considered further in the general discussion of our results.

An additional impetus for the present experiments was that Hall, Ewing, Tinzmann, and Wilson (1981) found equivalent susceptibility to phonemic-confusion effects when a small group of adolescents and adults who were severely retarded in reading were compared with normal readers. The result was obtained under circumstances in which scaling problems of the sort discussed above seemed to be absent, and at the very least it raises questions regarding the generality of the conclusions reached by Shankweiler et al. (1979).

Given the points raised above, together with the influential role of the Mann et al. (1980) and Shankweiler et al. (1979) studies in the development of theory regarding reading deficiency, it seemed sensible to examine this matter more fully. This is what we attempted to do in the five experiments now to be reported. Experiments 1-3 examined immediate serial recall of rhyming and nonrhyming letter strings, roughly paralleling the Shankweiler et al. (1979) experiments. Experiment 4 used word lists, rather than letter lists, as in Mann et al. (1980). Experiment 5 was conducted to illustrate the consequences of variations in the difficulty level of the letter-recall task insofar as task sensitivity to phonemicsimilarity effects is concerned.

\section{EXPERIMENT 1}

In Experiment 1, rhyming and nonrhyming strings of letters were presented visually for immediate serial recall by children varying in reading ability. The materials and procedures used followed closely those of Shankweiler et al. (1979, Experiment 1), but with certain significant departures. Instead of their group testing procedures, which required written responses (which we thought might be especially disadvantageous to poor readers), the children were tested individually and with aural recall. Second, recall always occurred immediately following presentation, whereas Shankweiler et al. used both an immediate and a 15-sec delay condition. Third, in selecting children with particular difficulties in reading (our poor readers), achievement tests in mathematics as well as in reading were used to exclude children whose achievement deficits were not primarily in reading. To increase the reliability of 
selection and to reduce statistical regression artifacts (see Hall \& Humphreys, 1982), the results of two tests of reading and two tests of mathematics achievement were used.

\section{Method}

Subjects. The subjects were selected from children in Grades 2 and 3 in two suburban school districts. As a first step in selecting the poor readers, a large group of children with reading scores at least 1 stanine below their mathematics scores were identified from school test records and then were administered the Reading, Mathematics, and Brief Cognitive scales of the Woodcock-Johnson Psycho-Educational Battery (Woodcock, 1977). The Brief Cognitive scale was used to provide an estimate of general intellectual ability. Children then were excluded if their reading scores were not at least 10 points below their math scores. The Woodcock-Johnson scores were standard scores with a mean of 100 and a standard deviation of 15 . Of those displaying such a discrepancy, children were excluded if their Brief Cognitive scores were closer to their reading scores than to their math scores, resulting in a final sample of 17 poor readers. The normal readers consisted of 15 children whose reading scores were as high as or higher than their mathematics scores both on the school-administered tests and on the Woodcock-Johnson scales, and with both scores in the average range or above. The Woodcock-Johnson scores of these samples are summarized in Table 1.

Materials. Eight four-letter and 8 five-letter lists of rhyming letters were formed by assigning the letters $D, G, T, V$, and $\mathrm{Z}$ randomly to lists (no letter appeared more than once in a given string). Eight four-letter and 8 five-letter nonrhyming lists were formed in the same manner from the letters $H, L, Q, R$, and $Y$. These 32 lists then were divided into four blocks of 8 lists each, with equal numbers of each list length and each list type (rhyming vs. nonrhyming) in each block. The order of lists within blocks and of the blocks within the total set of 32 lists was determined randomly.

Procedure. The lists were presented on the CRT of an Apple II microcomputer. Presentation of letters was successive, and each letter was exposed for $1 \mathrm{sec}$. Presentation of each list was preceded by a warning tone, and the last letter was immediately followed by a bell tone to signal recall. Administration of the 32 lists was preceded by an explanation of and practice on the task. The ability of each child to name each of the letters also was ensured at the beginning of the experimental session.

\section{Results}

Recall scores for each list were determined by adding the number of letters recalled in the correct positions. These position scores reflect both item and order information, as did the error scores used by Shankweiler et al. (1979). The data are summarized in Table 2. Separate unweighted-means analyses of variance (ANOVAs) were applied for each list length, with essentially identical results. The most pertinent of the results was the absence of any hint of a significant groups $x$ list type interaction (both $\mathrm{Fs}<1$ ) in the presence of a strong effect of list type $[F(1,30)=14.98, \mathrm{MSe}=88.30$, and $\mathrm{F}(1,30)=66.76, \mathrm{MSe}=25.38$, for four- and five-letter lists, respectively; $p<.01$ in each case]. Fourteen of the 17 poor readers and 14 of the 15 normal readers were higher on nonrhyming than on rhyming lists. Although the average performance of the normal readers was higher than that of the poor readers, variability within
Table 1

Sample Characteristics for Experiments 1 and 2

\begin{tabular}{lrrrr}
\hline & \multicolumn{4}{c}{ Woodcock-Johnson Means } \\
\cline { 3 - 5 } \multicolumn{1}{c}{ Group } & CA & Reading & Math & IQ \\
\hline \multirow{4}{*}{ Normal Readers } & 7.8 & 114.6 & 106.3 & 104.1 \\
Poor Readers & 8.1 & 89.8 & 103.4 & 104.4 \\
& \multicolumn{5}{c}{ Experiment 1} \\
Normal Readers & 8.4 & 106.2 & 97.7 & 99.9 \\
Poor Readers & 8.8 & 87.9 & 105.2 & 101.0 \\
& Experiment 3 & & \\
Normal Readers & 8.7 & 108.5 & 108.0 & 104.6 \\
Poor Readers & 8.2 & 86.3 & 106.6 & 105.0 \\
Low Ability & 8.6 & 82.7 & 86.0 & 82.3 \\
\hline
\end{tabular}

Note $-C A=$ chronological age.

Table 2

Position-Score Means in Experiments 1 Through 4

\begin{tabular}{|c|c|c|c|c|}
\hline \multirow[b]{2}{*}{ Group } & \multicolumn{2}{|c|}{ Four-Letter Lists } & \multicolumn{2}{|c|}{ Five-Letter Lists } \\
\hline & $\begin{array}{c}\text { Non- } \\
\text { rhyming }\end{array}$ & Rhyming & $\begin{array}{c}\text { Non- } \\
\text { rhyming }\end{array}$ & Rhyming \\
\hline \multicolumn{5}{|c|}{ Experiment 1} \\
\hline $\begin{array}{l}\text { Normal Readers } \\
\text { Poor Readers }\end{array}$ & $\begin{array}{l}21.87 \\
20.94\end{array}$ & $\begin{array}{l}12.53 \\
12.06\end{array}$ & $\begin{array}{l}21.80 \\
19.41\end{array}$ & $\begin{array}{l}10.53 \\
10.06\end{array}$ \\
\hline \multicolumn{5}{|c|}{ Experiment 2} \\
\hline $\begin{array}{l}\text { Normal Readers } \\
\text { Poor Readers }\end{array}$ & $\begin{array}{l}30.86 \\
28.87\end{array}$ & $\begin{array}{l}19.29 \\
15.47\end{array}$ & $\begin{array}{l}32.21 \\
26.20\end{array}$ & $\begin{array}{l}12.43 \\
10.73\end{array}$ \\
\hline \multicolumn{5}{|c|}{ Experiment 3} \\
\hline $\begin{array}{l}\text { Normal Readers } \\
\text { Poor Readers } \\
\text { Low Ability }\end{array}$ & $\begin{array}{l}27.87 \\
27.29 \\
20.18\end{array}$ & $\begin{array}{l}16.40 \\
19.36 \\
12.00\end{array}$ & $\begin{array}{l}29.73 \\
29.12 \\
13.91\end{array}$ & $\begin{array}{r}13.53 \\
14.50 \\
8.91\end{array}$ \\
\hline \multicolumn{5}{|c|}{ Experiment 4} \\
\hline $\begin{array}{l}\text { Normal Readers } \\
\text { Poor Readers }\end{array}$ & & & $\begin{array}{l}17.93 \\
13.00\end{array}$ & $\begin{array}{r}11.53 \\
8.73\end{array}$ \\
\hline
\end{tabular}

Note-Maximum possible scores were 32 for four-letter lists and 40 for five-letter lists.

groups was very high, and the between-groups difference did not reach significance.

Similar analyses were performed on other scores, including the error scores used by Shankweiler et al. (1979), on order scores (see Wickelgren, 1965), and on more lenient scores in which order was ignored. In each case, there was no evidence of a groups $x$ list type interaction. Thus, the experiment offers no support for the notion that children with low reading achievement are generally less likely to generate phonetic or acoustic representation of visually presented letters.

\section{EXPERIMENT 2}

This experiment was similar to Experiment 1, except that presentation was auditory, as it was in the third experiment reported by Shankweiler et al. (1979). The 
subjects averaged about 1 year older than those in Experiment 1 , and the procedures for sample selection, although basically similar, differed in certain details.

\section{Method}

Subjects. All the subjects were selected from Grades 3 and 4 of two suburban public school districts near Chicago. The first stage in selecting the poor readers consisted of identifying, through school records, children with reading scores in the 4 th stanine or below with math scores at least 2 stanines higher. These children were given the Woodcock-Johnson tests as in Experiment 1, and were retained in the final sample $(n=14)$ only if their math scores exceeded their reading scores by at least 6 scale score points and if both the math and the Brief Cognitive scores were in the normal range.

To select the normal readers, children in several classrooms were given the three Woodcock-Johnson tests until 14 children were found whose reading achievernent was above 95 and whose math and Brief Cognitive scores were in the same range as those for the poor readers. Basic sample characteristics are summarized in Table 1.

Materials and Procedure. The materials and procedure differed from those of Experiment 1 in just two respects. First, the pools of letters from which the lists were constructed consisted of $B, C, D, G, P, T, V$, and $Z$ for the rhyming lists and $H$, $K, L, Q, R, S, W$, and $Y$ for the nonrhyming lists. Second, presentation was auditory, using a tape recorder with tones to signal the beginning and end of each list.

\section{Results}

The position scores were calculated as in Experiment 1 , and these data also are summarized in Table 2 . Again, the main effect of list type was highly reliable $[F(1,27)=120.76, \mathrm{MSe}=19.01$, for four-letter lists and $\mathrm{F}(1,27)=145.17, \mathrm{MSe}=31.11$, for five-letter lists; $\mathrm{p}<.01$ for both], but the groups $x$ list type interaction was not significant for either list length. Every subject in each group scored higher on the nonrhyming than on the rhyming lists. The only result that differed from that of Experiment 1 was in the main effect of groups, for which the normal readers were reliably $(\mathrm{p}<.05)$ higher $\mid \mathrm{F}(1,27)=5.12, \mathrm{MSe}=23.24$, for fourletter lists and $\mathrm{F}=4.55, \mathrm{MSe}=48.13$, for five-letter lists]. In short, the normal readers were somewhat better than the poor readers in overall performance, but were neither more nor less susceptible to confusion produced by the rhyming letters. Analyses performed on other scores (e.g., order scores) again yielded the same essential results.

\section{EXPERIMENT 3}

The principal difference between this and the previous experiment was the inclusion of an additional group (the low-ability group) of children below average in math and in general intelligence as well as below average in reading. Given the correlation generally found between memory-span tasks and general intelligence, one might expect this group to be markedly below the normal readers in performance on the nonrhyming letters, particularly on the more difficult five-letter lists. If so, and according to the reasoning outlined earlier, this should create the kind of scaling problem that could result in a spurious interaction between groups and list type in the case of the five-letter lists.

\section{Method}

The experimental materials and procedures were as in Experiment 2. The subjects all were enrolled in Grade 3 or 4 of public suburban elementary schools. The normal readers consisted of 14 children who met two consecutively applied sets of criteria: (1) reading and math scores within 1 stanine of each other and at the 5 th stanine or above, according to school records of standardized achievement test performance, and (2) scores above 95 on the Woodcock-Johnson Brief Cognitive, Reading, and Math tests, with less than a 5-point discrepancy between the latter two. The 15 poor readers were: (1) below the 5 th stanine in reading, with math scores at least 3 stanines higher on schooladministered achievement tests, and (2) below 95 in reading, at least 10 points higher in math, and above 90 in general intelligence, on the three Woodcock-Johnson tests. The low-ability children were below 90 on all three Woodcock-Johnson tests. Test scores are summarized in Table 1.

\section{Results}

The position-score data are summarized in Table 2 , in which it appears that both the normal readers and the poor readers suffered heavily and about equally from phonetic similarity. This was confirmed by a highly significant effect $(p<.01)$ of list type, both for fourletter lists $[F(1,27)=75.11, \mathrm{MSe}=18.14]$ and for fiveletter lists $[F(1,27)=334.17, \mathrm{MSe}=10.29]$, along with nonsignificance for groups (normal readers vs. poor readers) and for the groups $x$ list type interaction $(F<1)$. All of the poor readers and all but one of the normal readers performed better on the nonrhyming than on the rhyming lists. Analyses using other scoring methods yielded essentially identical results.

Consider next the performance of the low-ability group relative to the normal readers, first with respect to the five-letter lists. Performance of that group was substantially and significantly below that of the normal readers $[F(1,25)=19.38, \mathrm{MSe}=68.40]$, and the significant groups $x$ list type interaction $[F=16.73, \mathrm{MSe}=$ 23.79] reflected the smaller effect of list type for the low-ability children. The main effect of list type also was significant $[F(1,25)=59.93, \mathrm{MSe}=23.79]$. All ps here were below .01. This pattern of data is similar to that for the good and poor readers in the Shankweiler et al. (1979) experiments, and suggests that the low-ability children were relatively insensitive to phonemic similarity among letters. However, interpretation of the critical interaction is clouded by the fact that the low. ability group performed much worse than the normal readers on the nonrhyming lists. For example, of those 11 children, three averaged fewer than one item per five-letter nonrhyming list, and four others averaged below two items. Among the 15 normal readers, all but two averaged above three items per five-item nonrhyming list. A groups $\mathrm{x}$ list type interaction under such circumstances is meaningless, leaving unresolved the 
question of a possible deficit in phonetic encoding. An examination of performance on the four-item lists suggests a resolution of the issue.

With the four-item lists, all but one of the low-ability children performed better on the nonrhyming lists than on the rhyming lists. That exception was a child who recalled, on the average, less than one letter per list across the eight lists, and thus could not be expected to show poorer performance on the rhyming lists, no matter how susceptible to phonemic similarity. With that subject's data removed, the mean position scores, expressed as percentages, were $67.5 \%$ for nonrhyming lists and $39.1 \%$ for rhyming lists. Clearly, this group of children was highly susceptible to the confusing effects of phonemic similarity. Whether the degree of such susceptibility was as great as for normal readers is more difficult to say with certainty because of the scaling problems we have discussed. However, looking back through our three experiments, we find instances in which difficulty levels for the normal readers are such that comparisons seem fruitful. One case is with the performance of the normal readers on four-letter lists in Experiment 1. The percentage means there were $68.3 \%$ for nonrhyming and $39.2 \%$ for rhyming lists. These are remarkably close to the four-letter-lists data for the low-ability subjects in Experiment 3. Another case is with the five-letter lists for the normal readers in Experiment 3, in which the respective mean percentages are $74.3 \%$ and $33.8 \%$. For both of these comparisons, a groups $\mathrm{x}$ list type ANOVA was applied, and in neither case was the interaction statistically significant. Thus, although these comparisons across experiments cannot be regarded as the best kind of evidence, they do suggest that the low-ability subjects are normally susceptible, or nearly so, to phonemic similarity.

\section{EXPERIMENT 4}

Our first three experiments were consistent in showing that children with low achievement, especially in reading, do display the usual phonemic confusion effect in letter-recall tasks. However, Mann et al. (1980) reported another set of experiments in which, again, group $\mathrm{x}$ list type interactions were observed, but this time with word lists and with sentences. As with the earlier Shankweiler et al. (1979) experiments, in each of these more recent experiments the poor readers were markedly lower than the good readers in performance on the nonrhyming items. To that extent, the interactions reported might be considered suspect. On the other hand, the materials were different (far more meaningful), and it seemed possible that, in this instance, poor readers might not show as great an effect of phonetic similarity. That would be consistent with the position advanced by Byrne and Shea (1979), who proposed that it is particularly on meaningful material that poor readers are less likely to encode phonetic information. Experiment 4 was conducted to address the issue; the experiment was similar to our Experiment 3, except that lists of unrelated familiar nouns were used instead of letters.

\section{Method}

Subjects. The poor readers consisted of the same 14 poor readers as in Experiment 2, plus one additional child identified through the same procedure. The normal readers were the same as those who participated in Experiment 2.

Design, Materials, and Procedure. Each subject was presented 12 five-word strings, 6 rhyming strings, and 6 nonrhyming lists for immediate serial recall. To construct these lists, 21 sets of one-syllable words, five rhyming words per set, were generated. Six of these sets then were selected randomly, and then ordered randomly, to serve as the rhyming lists. Thus, each of the 6 rhyming lists consisted of a different set of five words (e.g., TAME, NAME, GAME, FAME, and CLAIM; FREE, BEE, $\mathrm{KEY}, \mathrm{SEE}$, and TREE). The nonrhyming lists were constructed from the remaining 15 sets of words; each rhyming list consisted of one word from each of 5 of these remaining 15 sets. The 12 lists then were ordered randomly for presentation. They were presented by tape recorder at a $1-\mathrm{sec}$ rate, followed by $10 \mathrm{sec}$ for aural recall. An alerting tone preceded each list, and a recall signal immediately followed the final word in the list. The session began with an explanation of the task, followed by brief practice.

\section{Results}

The results, summarized in Table 2, are similar to those of Experiments 1-3. An ANOVA applied to the position scores for the poor and normal readers yielded a significant effect only for list type $[F(1,28)=34.90$, $\mathrm{MSe}=12.22, \mathrm{p}<.01]$, although the main effect of groups approached significance $[\mathrm{F}(1,28)=4.04, \mathrm{MSe}=$ $55.48, p<.06]$. The interaction between these variables did not approach significance $(F=1.40)$. The hint of a groups $\mathrm{x}$ list type interaction that is present was due primarily to the very low scores of three poor readers on nonrhyming lists: One child recalled only one word in the correct position over six nonrhyming lists, another recalled only four, and another, just five. No normal readers recalled as few words. Thus, Experiment 4 offered no evidence of differential susceptibility of the two groups to phonemic similarity among words.

\section{EXPERIMENT 5}

This experiment explored further the notion that phonemic-confusion effects in the letter-recall task are diminished when task difficulty is high. This was done by administering rhyming and nonrhyming letter lists to college students under either standard or high-difficulty conditions. The standard condition was similar procedurally to the procedures used in the previous experiments. The high-difficulty condition differed only in the insertion of a very brief auditory counting task between presentation and test, presumably generating interference with recall of the letters being held (or recycled) in some sort of auditory store.

\section{Method}

The subjects, 12 Northwestern students, were administered four blocks of seven-letter lists, two rhyming blocks and two 
nonrhyming blocks, with 12 lists per block. Half the subjects received the blocks in the order: rhyming, nonrhyming, rhyming, nonrhyming. That order was reversed for the remaining six subjects. The first two blocks always were administered under standard conditions, that is, with auditory presentation at a $1-\sec$ rate and with immediate written recall. The last two blocks were administered under the high-difficulty condition, which differed only in requiring the subject to count backward three numbers from some arbitrary number (differing each time) before giving the letters.

\section{Results}

The means of the position scores (maximum score $=$ 84) were 58.92 for the nonrhyming lists and 34.67 for the rhyming lists under the standard presentation conditions. Clearly, the usual phonemic effect obtained here. The corresponding means under high-difficulty conditions were 26.00 and 23.67. Here we see a complete washout of the phonemic-confusion effect. Results of the list type $x$ retention interval (difficulty level) ANOVA applied to the position scores yielded significant effects of list type $[F(1,44)=52.89]$ and of retention interval $[F(1,44)=133.14]$, and a significant interaction between them $[F(1,44)=28.99, \mathrm{MSe}=43.48] ; \mathrm{p}$ was less than .01 in each case. It is clear that one would not characterize these subjects as immune to acoustic confusion, yet this is just the conclusion suggested by the data under the high-difficulty condition taken alone.

There are two ways to look at these results. The interpretation we had intended is that the interference produced by the counting task was so deleterious to performance that the usual interference effects of phonemic similarity could not be detected. As a reviewer pointed out, though, one could turn this interpretation around and say that the interference from the counting task was minimal in the rhyming condition because interference from phonemic similarity already was so great. Thus, only the nonrhyming lists were adversely affected to a marked degree by the counting task. Whichever of these is preferred, the results do seem to illustrate that the serial-recall task can be insensitive to phonemic-similarity effects under certain circumstances and with subjects who can easily be shown to be susceptible to such effects.

\section{GENERAL DISCUSSION}

Our results suggest that children with achievement deficits centered in reading are normally susceptible to phonemic confusions in tasks requiring immediate serial recall of letters and words. In each of our four experiments relevant to this issue, the task was at a difficulty level that was sensitive to phonemic-similarity effects, and the difference between groups in performance on nonrhyming strings was relatively small. This means that the experiments should have detected differences between groups in susceptibility to phonemic similarity and that such differences (group $\mathrm{x}$ list type interactions) would be fully interpretable. In fact, no such differences were observed; in each of four experiments, both the poor and the normal readers showed a large and roughly similar deleterious effect of phonemic similarity. Although the interpretation of null results can be problematic, the consistency of our results across experiments seems convincing. At the very least, it appears that the true differences between the populations that we sampled must be very small in this respect.

Our results appear to be in sharp conflict with those of Mann et al. (1980) and Shankweiler et al. (1979) described earlier. We shall consider two possible explanations of that discrepancy, the first of which pertains to the measurement issue raised earlier.

Our proposal is that the sensitivity of the immediateserial-recall task to phonemic-similarity effects is highly dependent on the difficulty level of the task when nonrhyming lists are presented. For example, if the task is made very easy by using only two- or three-letter lists, one would hardly expect much difference between rhyming and nonrhyming lists, even for subjects who are profoundly affected by phonemic similarity when somewhat longer (more difficult) lists are used. More relevant to the present situation, the serial-recall task also becomes relatively insensitive to phonemic-similarity effects when task difficulty is very high. This insensitivity was demonstrated in two of our experiments. In Experiment 3, with the low-ability group, a large effect of phonemic similarity was found for the four-letter lists, indicating that those low-ability children were, indeed, highly susceptible to the deleterious effect of phonemic similarity. However, with the five-letter strings, which were considerably more difficult for the low-ability group than for the other groups, the phonemicsimilarity effect was relatively small. If we had used only five-letter lists and had followed the Shankweiler et al. (1979) reasoning, we would have concluded, incorrectly it seems, that the low-ability children were far less susceptible to phonemic similarity than are more able children.

Experiment 5 further illustrated this difficultylevel problem. Here the sort of interaction found by Shankweiler et al. (1979) was produced within subjects by the experimental manipulation of difficulty level. It seems reasonable to assume that the university students who served as subjects were superior readers, yet they showed virtually no sensitivity to phonemic similarity under the high-difficulty conditions. Quite obviously, that result was simply an artifact of the very high difficulty level of the task, given that these same students displayed a very large phonemic-confusion effect at a moderate level of task difficulty.

As we see it, there are two main implications of the relationship between task difficulty and task sensitivity to phonemic-similarity effects. A general implication is that when different subject populations are being compared, one must take pains to ensure that task difficulty is at an appropriate and similar level for the groups being compared (see also Baron \& Treiman, 1980, for a more complete discussion of such problems and potential solutions). The second and more specific implication is 
that the interactions between groups (good and poor readers) and list type (nonrhyming and rhyming letter lists) reported by Mann et al. (1980) and Shankweiler et al. (1979) do not provide convincing evidence of differential susceptibility of the groups to phonemicsimilarity effects. That is because, in every one of their experiments, there was a large difference between the groups in the difficulty level of the nonrhyming lists. In short, the Mann et al. data and the Shankweiler et al. data left unsettled the question of differential sensitivity of their good and poor readers to phonemic similarity. To settle that question requires that the groups be compared under appropriate conditions with respect to task difficulty, conditions that we believe obtained in our Experiments 1-4.

What are the implications of our results for a phoneticdeficit hypothesis regarding the origin of reading difficulties? Our findings seem to argue quite strongly against certain possibilities, including the idea that children with deficits specific to reading are fundamentally less able than are normal readers to generate phonetic codes for visually or orally presented items. Also, it does not seem that they are less likely to do so, at least in short-term memory tasks with highly familiar items. Another possibility that seems to be ruled out is that their phonetic codes are fundamentally of a lower quality. If their codes were present but degraded in some way, one might expect that items that were similar phonemically would be often more difficult for them than for children with more distinctive phonetic representations. That is, one might expect a group $\mathrm{x}$ list type interaction of just the opposite sort from that found by Shankweiler et al. (1979) if low readers' phonetic codes were lower in quality.

Our data do not preclude the possibility of less or lower quality phonemic information by poor readers when the task is more lifelike than is the immediateserial-recall task. Byrne and Shea (1979) proposed, and offered supporting evidence, that poor readers tend to focus more on semantic features and less on surface (e.g., phonemic) features of words than do good readers. Our data do not support this idea, but neither do they provide strong evidence against it. Byrne and Shea's evidence derived from a recognition memory task involving more items and slower presentation rates than were used in our experiments, and with sampling procedures that did not systematically exclude the general underachiever. One or more of these differences may account for the apparent conflict between our results and theirs.

We have suggested that the critical interactions obtained by Mann et al. (1980) and Shankweiler et al. (1979) would not have occurred had task difficulty been similar for their good and poor readers. There is, however, another possibility that cannot be ruled out by our data. That alternative is that each result is correct but each applies to a different subpopulation of poor readers. Given our sampling procedures, our results seem to apply to poor readers who in general are bright and achieving (our poor readers) and to children who are low generally in achievement (including reading) and in intelligence (our low-ability group). Judging by their sampling procedures, the Mann et al. and Shankweiler et al. samples included a third subpopulation, namely, bright children with general achievement problems. Perhaps it was the performance of that subset of their samples that accounted for the observed interactions. This would mean, then, that relative insensitivity to phonemic similarity is characteristic of the general underachiever (in traditional educational nomenclature) but not of children with achievement deficits specific to reading or of those low in general achievement and intelligence. This possibility cannot be ruled out, but it seems less plausible than our scaling explanation, especially in light of very recent data by Alegria, Pignot, and Morais (1982) in which the phonemicconfusion effect with rhyming words was as great for the best as for the worst readers among a group of firstgrade children.

There is a second discrepancy between the two sets of studies, and we suspect that discrepancy is accounted for largely by the sampling differences between them. In both the Mann et al. (1980) and the Shankweiler et al. (1979) experiments, there was a very large inferiority of the poor readers on nonrhyming letter and word strings, as pointed out earlier. In our experiments, the group difference was, at best, small. This discrepancy between the two sets of experiments may very well be due to the inclusion of the general underachiever in the Mann et al. and the Shankweiler et al. samples but not in ours. It seems plausible to us that the generally poor achiever is more likely to be characterized by less effortfulness on intellectual tasks than is the child with a record of good achievement except in reading. Although this account seems quite reasonable, it cannot, of course, be verified by our data.

\section{REFERENCES}

Alegria, J., Pignot, E., \& Morais, J. Phonetic analysis of speech and memory codes in beginning readers. Memory \& Cognition, 1982, 10, 451-456.

Baron, J., \& Treiman, R. Some problems in the study of differences in cognitive processes. Memory \& Cognition, 1980, 24, 116-119.

Byrne, B., She A, P. Semantic and phonetic memory codes in beginning readers. Memory \& Cognition, 1979, 7, 333-338.

Hall, J. W., Ewing, A., Tinzmann, M. B., \& Wilson, K. P. Phonetic coding in dyslexics and normal readers. Bulletin of the Psychonomic Society, 1981, 17, 177-188.

Hall, J. W., \& Humphreys, M. S. Research on specific learning disabilities: Deficits and remediation. Topics in Learning and Learning Disabilities, 1982, 2, 68-78.

Lortus, G. R. On interpretation of interactions. Memory \& Cognition, 1978, 6, 312-319.

ManN, V. A., Liberman, I. Y., \& Shankweiler, D. Children's 
memory for sentences and word strings in relation to reading ability. Memory \& Cognition, 1980, 8, 329-335.

Morrison, F. J., \& Manis, F. R. Cognitive processes and reading disability: A critique and proposal. In C. J. Brainerd \& M. Pressley (Eds.), Advances in cognitive development (Vol. 2) Verbal processes in development. New York: Springer-Verlag, 1982.

Shankweiler, D., Liberman, I. Y., Mark, L. S., Fowler, C. A., \& Fische R, F. W. The speech code and learning to read. Journal of Experimental Psychology: Human Learning and Memory, 1979, 5, 531-545.
Vellutino, F. R. Dyslexia: Theory and research. Cambridge, Mass: MIT Press, 1979.

Wickelgren, W. A. Phonetic similarity and interference in shortterm memory for single letters. Journal of Experimental Psy. chology, 1966, 71, 396-404.

WooDcock, R. W. Woodcock-Johnson psycho-educational battery. Boston, Mass: Teaching Resources, 1977.

(Manuscript received March 10, 1983;

revision accepted for publication June 23, 1983.) 